Western University

Scholarship@Western

8-1-2014

\title{
Pulmonary ventilation defects in older never-smokers
}

Khadija Sheikh

Gregory A Paulin

Sarah Svenningsen

Miranda Kirby

Nigel A M Paterson

See next page for additional authors

Follow this and additional works at: https://ir.lib.uwo.ca/biophysicspub

Part of the Medical Biophysics Commons

\section{Citation of this paper:}

Sheikh, Khadija; Paulin, Gregory A; Svenningsen, Sarah; Kirby, Miranda; Paterson, Nigel A M; McCormack, David G; and Parraga, Grace, "Pulmonary ventilation defects in older never-smokers" (2014). Medical Biophysics Publications. 113.

https://ir.lib.uwo.ca/biophysicspub/113 


\section{Authors}

Khadija Sheikh, Gregory A Paulin, Sarah Svenningsen, Miranda Kirby, Nigel A M Paterson, David G McCormack, and Grace Parraga 


\title{
Pulmonary ventilation defects in older never-smokers
}

\author{
Khadija Sheikh, ${ }^{1,2}$ Gregory A. Paulin, ${ }^{1,2}$ Sarah Svenningsen, ${ }^{1,2}$ Miranda Kirby, ${ }^{1,2}$ Nigel A. M. Paterson, ${ }^{3}$ \\ David G. McCormack, ${ }^{3}$ and Grace Parraga ${ }^{1,2}$ \\ ${ }^{1}$ Imaging Research Laboratories, Robarts Research Institute, London, Ontario, Canada; ${ }^{2}$ Department of Medical Biophysics, \\ University of Western Ontario, London, Ontario, Canada; ${ }^{3}$ Division of Respirology, Department of Medicine, University of \\ Western Ontario, London, Ontario, Canada
}

Submitted 22 January 2014; accepted in final form 29 May 2014

\begin{abstract}
Sheikh K, Paulin GA, Svenningsen S, Kirby M, Paterson NA, McCormack DG, Parraga G. Pulmonary ventilation defects in older never-smokers. J Appl Physiol 117: 297-306, 2014. First published June 5, 2014; doi:10.1152/japplphysiol.00046.2014.—Hyperpolarized ${ }^{3} \mathrm{He}$ MRI previously revealed spatially persistent ventilation defects in healthy, older compared with healthy, younger neversmokers. To understand better the physiological consequences and potential relevance of ${ }^{3} \mathrm{He}$ MRI ventilation defects, we evaluated ${ }^{3} \mathrm{He}-\mathrm{MRI}$ ventilation-defect percent (VDP) and the effect of deep inspiration (DI) and salbutamol on VDP in older never-smokers. To identify the potential determinants of ventilation defects in these subjects, we evaluated dyspnea, pulmonary function, and cardiopulmonary exercise test (CPET) measurements, as well as occupational and second-hand smoke exposure. Fifty-two never-smokers $(71 \pm 6$ yr) with no history of chronic respiratory disease were evaluated. During a single visit, pulmonary function tests, CPET, and ${ }^{3} \mathrm{He}$ MRI were performed and the Burden of Obstructive Lung Disease questionnaire administered. For eight of 52 subjects, there was spirometry evidence of airflow limitation (Global Initiative for Chronic Obstructive Lung Disease-Unclassified, I, and II), and occupational exposure was reported in 13 of 52 subjects. In 13 of 52 (25\%) subjects, there were no ventilation defects and in 39 of 52 (75\%) subjects, ventilation defects were observed. For those subjects with ventilation defects, six of 39 showed a VDP response to DI/salbutamol. Ventilation heterogeneity and VDP were significantly greater, and forced expiratory volume in $1 \mathrm{~s}\left(\mathrm{FEV}_{1}\right) /$ forced vital capacity was significantly lower $(P<0.05)$ for subjects with ventilation defects with a response to $\mathrm{DI} /$ salbutamol than subjects with ventilation defects without a response to DI/salbutamol and subjects without ventilation defects. In a step-wise, forward multivariate model, $\mathrm{FEV}_{1}$, inspiratory capacity, and airway resistance significantly predicted VDP $\left(R^{2}=0.45, P<\right.$ $0.001)$. In conclusion, most never-smokers had normal spirometry and peripheral ventilation defects not reversed by DI/salbutamol; such ventilation defects were likely related to irreversible airway narrowing/collapse but not to dyspnea and decreased exercise capacity.
\end{abstract}

bronchodilation; cardiopulmonary exercise testing; deep inspiration; pulmonary aging; ${ }^{3} \mathrm{He}$ MRI

PULMONARY AGING IS CONCOMITANT with changes in elastic recoil $(10,42,43)$, chest-wall compliance $(10,43)$, and respiratory muscle strength $(8,21)$. In concert with these physiological changes, functional residual capacity (FRC), residual volume (RV), and airway resistance (Raw) also increase (21), whereas the forced expiratory volume in $1 \mathrm{~s}\left(\mathrm{FEV}_{1}\right)$, forced vital capacity (FVC) (9), and inspiratory capacity (IC) decrease (35).

Healthy, older adults may experience breathlessness during everyday activities $(1,17,19,30,41)$, and this is related to mortality risk $(1,19,41)$. In addition, in older adults, cardio-

\footnotetext{
Address for reprint requests and other correspondence: G. Parraga, Imaging Research Laboratories, Robarts Research Institute, 1151 Richmond St., London, Ontario, Canada N6A 5B7 (e-mail: gparraga@ robarts.ca).
}

pulmonary exercise test (CPET) measurements (3) correlate more strongly with overall health status than do measurements of resting lung function (3a, 12, 33). Moreover, CPET measurements show that in "normal," healthy aging, there is lower exercise-related oxygen uptake $\left(\mathrm{VO}_{2}\right)$, as well as greater minute ventilation $\left(\mathrm{V}_{\mathrm{E}}\right)$ and increased respiratory exchange ratio (RER) $(16,23,24)$. Recent studies have also shown that during exercise, significant ventilatory impairment is possible without increased dyspnea or premature exercise limitation (13).

The role of occupational and second-hand tobacco smoke exposure is important to acknowledge and understand in both normal and accelerated lung aging. In this context, the Burden of Obstructive Lung Disease (BOLD) study (5) showed that in never-smokers, the prevalence of airflow limitation consistent with chronic obstructive pulmonary disease (COPD) was as high as $30 \%$. The BOLD study also revealed the critical relationships in never-smokers among airflow limitation and age, history of occupational exposure, and childhood respiratory disease (28).

${ }^{3} \mathrm{He}$ ventilation MRI provides high-resolution, noninvasive measurements of lung function $(27,37)$ and identifies those regions of the lung that participate in ventilation and those that do not $(27,36)$. In healthy, young subjects, a single inhalation of hyperpolarized ${ }^{3} \mathrm{He}$ gas results in homogeneous lung filling, but in older never-smokers, characteristic "focal" ventilation defects are observed, corresponding to poorly ventilated lung regions $(36,37)$. In older never-smokers, ventilation defects are commonly observed on the lung periphery and the dependent lung regions, and this is in contrast with COPD and asthma, where numerous and large defects are heterogeneously distributed throughout the lung $(6,27,37)$.

The finding of spatially and temporally persistent ${ }^{3} \mathrm{He}$ MRI ventilation defects in older never-smokers with normal spirometry $(36,37)$ raises questions about the physiological meaning of ventilation defects in all subjects. For example, as shown previously, ${ }^{3} \mathrm{He}$ MRI ventilation abnormalities induced by methacholine challenge in young, healthy volunteers were reversed by deep inspiration (DI) (44). In young asthmatics, salbutamol inhalation reduced ventilation defects observed with ${ }^{3} \mathrm{He}$ MRI after methacholine challenge (40), but the effect of DI was not investigated. Raw measurements determined that asthmatic subjects cannot maximally dilate their airways and that the dilation that does occur after DI constricts back to baseline much faster than in healthy subjects (22). This suggested that in asthma, ventilation defects were related to salbutamol-responsive airway abnormalities, whereas in healthy volunteers, ventilation defects may reflect normal airway smooth muscle behavior that is reversible using DI.

We hypothesized that in older never-smokers, narrowed or collapsed airways were responsible for the persistent ventila- 
tion defects observed, and these would be responsive to and improve following DI. To test this hypothesis, we evaluated the effect of both DI and salbutamol on ${ }^{3} \mathrm{He}$ ventilation defects in a relatively large group of older never-smokers with no history of respiratory disease. We also evaluated the relationship of ventilation defects with occupational exposures, pulmonary function, and CPET measurements.

\section{MATERIALS AND METHODS}

Study subjects and logistics. All subjects provided written, informed consent to a study protocol approved by a Local Research Ethics Board and Health Canada. Subjects were enrolled between the ages of 60 and $90 \mathrm{yr}$ with a smoking history of $<0.5$ pack-years and no history of chronic respiratory or cardiovascular disease. After providing consent, all subjects made a single, 2- to 3-h visit and underwent the following evaluations in the same order: 1) BOLD occupational questionnaire (5), 2) spirometry, 3) plethysmography and the diffusing capacity of carbon monoxide (DLCO), 4) CPET, including dyspnea score, and 5) MRI. Pulmonary function tests were completed in $\sim 45 \mathrm{~min}$, followed by CPET, which was completed in 10-15 min. MRI was performed following CPET, and for subjects who did not have ventilation defects and those with defects that responded to DI, MRI was completed within 10-15 min. For subjects who were administered salbutamol, MRI was performed 25-30 min post-salbutamol inhalation.

Questionnaire. All subjects completed the BOLD occupational questionnaire (5) with exposures defined as described previously (28), including: 1) organic dust (farming; flour, feed, or grain milling; and cotton or jute processing), 2) inorganic dust (working with asbestos; hard-rock mining; coal mining; sandblasting; and foundry or steel milling), and 3) irritant gases (welding; firefighting; and chemical or plastics manufacturing). We also queried subjects directly about spousal and/or life-partner smoking history and recorded potential household second-hand smoke exposure.

Pulmonary function and CPETs. Spirometry was performed using an EasyOne spirometer (ndd Medizintechnik, Zurich, Switzerland), according to American Thoracic Society (ATS) guidelines (31). Body plethysmography was performed for the measurement of lung volumes, and DL $\mathrm{CO}_{\mathrm{C}}$ was measured using the gas analyzer (MedGraphics, St. Paul, MN). IC, defined as the volume change recorded at the mouth when taking a slow, full inspiration from a position of passive end-expiration, was measured using body plethysmography (31), as was Raw, defined as the pressure difference/unit flow. Post-DI pulmonary function tests were not performed, but for subjects administered salbutamol, FEV ${ }_{1}$ and FVC were recorded, 35-40 min postinhalation and upon completion of MRI.

After completion of pulmonary function tests, all subjects performed CPET using a cycle ergometer (Ultima PFX; MedGraphics), according to ATS guidelines (3a), with a 2-min warm-up with no resistance, followed by a $20-\mathrm{W}$ incremental increase in work rate. Subjects were required to pedal at a frequency of $60 \mathrm{rpm}$ with increasing work rate until the ventilatory anaerobic threshold was reached. Ventilatory anaerobic threshold was defined as the time when $\mathrm{CO}_{2}$ production increased disproportionately in relation to $\mathrm{VO}_{2}$. The ventilatory anaerobic threshold was determined by onboard software for the CPET unit, which used an iterative regression and analysis of slope. Subjects continued exercise until fatigue was reported. $\mathrm{VO}_{2}$, RER, work rate (i.e., power), as well as $\mathrm{V}_{\mathrm{E}}$ were measured at rest, at the ventilatory anaerobic threshold, and when maximum pulmonary $\mathrm{VO}_{2}\left(\mathrm{VO}_{2} \mathrm{max}\right)$ was reached. The time taken to reach $\mathrm{VO}_{2}$ max was also recorded. CPET measurements, including $\mathrm{VO}_{2}$, power, and $\mathrm{V}_{\mathrm{E}}$, were adjusted for age, sex, and height using percent-predicted values reported previously $(11,16,24)$. Borg dyspnea and leg discomfort scales were used before and after exercise.
Image acquisition. MRI was performed after completion of all pulmonary function and CPETs on a 3.0 Tesla MR750 (GE Healthcare, Milwaukee, WI) system, as described previously (37), using a whole-body gradient set with a maximum gradient amplitude of 1.94 $\mathrm{G} / \mathrm{cm}$ and a single-channel, rigid elliptical transmit/receive chest coil (Rapid Biomedical GmbH, Rimpar, Germany). For both ${ }^{1} \mathrm{H}$ and ${ }^{3} \mathrm{He}$ MRI, subjects were instructed to inhale a gas mixture from a 1-liter Tedlar bag (Jensen Inert Products, Coral Springs, FL) from FRC, and image acquisition was performed during a 16-s breath-hold. Coronal (anatomical) ${ }^{1} \mathrm{H}$ MRI was performed using the whole-body radiofrequency coil and ${ }^{1} \mathrm{H}$ fast-spoiled, gradient-recalled echo sequence using a partial echo $[16 \mathrm{~s}$ total data acquisition; repetition time (TR)/echo time (TE)/flip angle $=4.7 \mathrm{~ms} / 1.2 \mathrm{~ms} / 30^{\circ}$, field of view $($ FOV $)=40 \times 40 \mathrm{~cm}$, bandwidth $=24.4 \mathrm{kHz}$, matrix $=128 \times 80$, 15-17 slices, $15 \mathrm{~mm}$ slice thickness, zero gap], as described previously (37). ${ }^{3} \mathrm{He}$ MRI static ventilation images were acquired using a fast-gradient echo method using a partial echo $(14 \mathrm{~s}$ total data acquisition; TR/TE/flip angle $=4.3 \mathrm{~ms} / 1.4 \mathrm{~ms} / 7^{\circ}, \mathrm{FOV}=40 \times 40$ $\mathrm{cm}$, bandwidth $=48.8 \mathrm{kHz}$, matrix $=128 \times 80,15-17$ slices, $15 \mathrm{~mm}$ slice thickness, zero gap).

Immediately after image acquisition at the scanner, while the subject was still in position, ${ }^{3} \mathrm{He}$ static ventilation images were qualitatively evaluated for ventilation abnormalities by a single, trained observer. If ${ }^{3} \mathrm{He}$ gas were homogeneously distributed throughout the lung, and there were no visible ventilation defects, then the subjects were classified as belonging to the no-defect group, and the session was deemed complete. In contrast, if ${ }^{3} \mathrm{He}$ gas were heterogeneously distributed throughout the lung and/or there were visually obvious ventilation defects, then the subject was classified as having ventilation defect(s). Upon qualitative inspection, subjects with visually obvious ventilation defects were instructed to perform DI. They were instructed to sit up while remaining on the scanner bed and to take four deep breaths in through their nose and out through their mouth. Imaging was performed immediately following DI. If defects persisted following DI, then the subject inhaled four puffs $(400 \mu \mathrm{g})$ of salbutamol while seated upright, and 25 min later, imaging was performed on a final occasion.

Image analysis. Based on visual inspection at the scanner, subjects were classified as: 1) no defects - those subjects without visually obvious ventilation defects, 2) subjects with ventilation defects that responded to DI or salbutamol, and 3) subjects with ventilation defects that did not respond to DI or salbutamol. ${ }^{3} \mathrm{He}$ MRI semiautomated segmentation was performed, as described previously (25), to generate ventilation-defect percent (VDP) - the ventilation defect volume (VDV) normalized to ${ }^{1} \mathrm{H}$ MRI thoracic cavity volume. Briefly, ${ }^{3} \mathrm{He}$ static ventilation images were segmented using a k-means approach that classified voxel-intensity values into five clusters, ranging from signal void [cluster $1(\mathrm{C} 1)$ or VDV] and hypointense [cluster 2 (C2)] to hyperintense signal [cluster 5 (C5)], therefore generating a gas distribution cluster map. For delineation of the ventilation-defect boundaries, a seeded, region-growing algorithm was used to segment the ${ }^{1} \mathrm{H}$ MRI thoracic cavity for registration to the cluster map, as described previously (25).

Ventilation heterogeneity was estimated, according to a previously described method (44), using the coefficient of variation (COV). A local COV, rather than a global COV, was generated (44) to ensure that local ventilation heterogeneity was not ignored. Briefly, for each voxel in a region of interest (ROI), a local ventilation heterogeneity value was calculated by computing the COV of the signal intensity in a $5 \times 5$ voxel neighborhood, which corresponded to a $244-\mathrm{mm}^{2}$ area centered on that voxel. To ensure that the $5 \times 5$ voxel neighborhood did not include voxels that were outside of the lungs, a signal-to-noise threshold of five was established. For example, any voxels that were in a neighborhood with an overall signal-to-noise ratio (SNR) of less than five were excluded from the COV computation. COV of the lung was calculated for each subject as in Eq. 1 


$$
\operatorname{COV}=\frac{\sqrt{\sum_{i=1}^{i=N} \frac{\sigma_{i}^{2}}{N}}}{\frac{\sum_{i=1}^{i=N} \mu_{i}}{N}}
$$

where $\sigma_{i}$ is the $\mathrm{SD}$ of the signal intensity of the $5 \times 5$ voxel neighborhood, $\mu_{i}$ is the mean signal intensity of the $5 \times 5$ voxel neighborhood, and $N$ is the number of ventilation ROIs in the lung. The ventilated lung ROI was defined as gas distribution cluster map C2-C5.

We also measured regional differences in VDP for the center nine, $15 \mathrm{~mm}$-thick slices using several different measurements, as shown in Fig. 1. The VDP gradient in the posterior-anterior (PA) direction was defined as the slope of the line that described the change in VDP from the most posterior slice in centimeters over the nine central slices (with a slice thickness of $15 \mathrm{~mm}$ each). The center nine slices were used to ensure that the static ventilation slices across subjects had adequate SNRs (i.e., SNR > 10) for VDP calculations, as well as to maintain an equal number of slices among all subjects. To calculate the gradient in the superior-inferior (SI) direction, the center nine coronal slices were reformatted into $15-\mathrm{mm}$ axial slices. The VDP SI gradient was defined as the slope of the line that described the change in VDP over the axial SI slices. In addition, the VDP difference between the most posterior and anterior slices (VDP $\triangle \mathrm{PA}$ ) was calculated, as was the VDP difference between the most superior and inferior slices (VDP $\Delta \mathrm{SI}$ ) of the central nine slices. The VDP located on the peripheral boundary of the lung (relative peripheral VDP) was estimated as the ratio of the VDV for the outermost 10 voxels of each slice (not including boundary voxels, defined as SNR $<2$ ) to the ${ }^{1} \mathrm{H}$ MRI thoracic-cavity volume. The proportion of ventilation defects located on the peripheral boundary was quantified as the ratio of peripheral lung VDV to whole-lung VDV (i.e., $\mathrm{VDV}_{\mathrm{Per}} / \mathrm{VDV}_{\mathrm{WL}}$ ).

Statistical analysis. ANOVA, multivariate regression, and post hoc analysis, using the Holm Bonferroni correction (45), were performed using SPSS 20.0 software (IBM, Armonk, NY). Paired sample $t$-tests were performed to determine the differences in VDP $\triangle \mathrm{PA}$ and VDP $\Delta$ SI using SPSS 20.0. We used the National Health and Nutrition Examination Survey III reference standards (14) for percent-predicted values. Univariate relationships were determined using regression $\left(r^{2}\right)$ and Pearson correlation coefficients $(r)$ for all subjects with GraphPad Prism V.6.00 (GraphPad Software, La Jolla, CA). Step-wise, multivariate regression was used to identify the predictors of VDP. The variables considered for modeling were chosen based on statistically significant, univariate relationships with VDP. Results were considered statistically significant when the probability of making a type I error was $<5 \%(P<0.05)$.

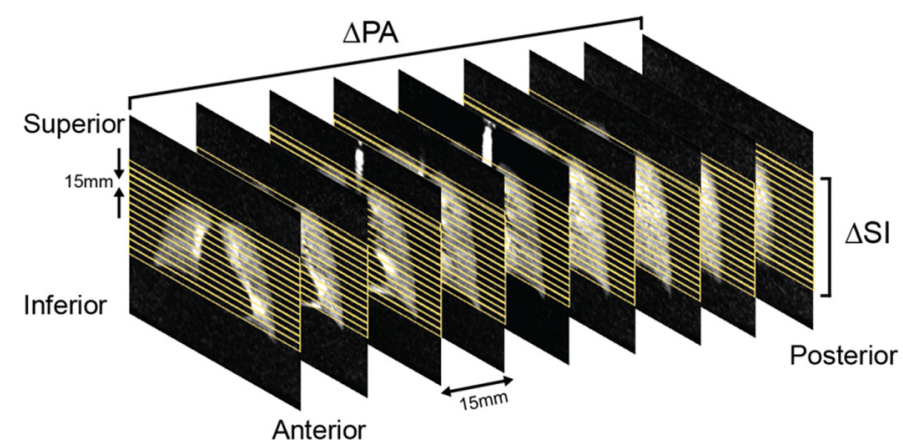

Fig. 1. Schematic for regional evaluation of ${ }^{3} \mathrm{He}$ MRI ventilation-defect percent (VDP). The central coronal static ventilation image slices $(9 \times 15 \mathrm{~mm})$ were evaluated. The lung was also divided into $15-\mathrm{mm}$ slices in the axial direction. The VDP $\Delta$ SI was defined as the difference between the most superior slice and the most inferior slice. The VDP $\triangle \mathrm{PA}$ was defined as the difference between the most posterior slice and the most anterior slice.

\section{RESULTS}

Subject data. As summarized in Table 1 (and a detailed subject listing in Table 2), 52 never-smokers (71 \pm 6 yr) completed all measurements during a single visit. In total, there were 13 of $52(25 \%)$ subjects without ${ }^{3} \mathrm{He}$ MRI ventilation defects and 39 of $52(75 \%)$ with ventilation defects. Of those subjects with ventilation defects, six (of 39, 15\%) showed a VDP response (i.e., visually obvious and quantitative decrease in VDP) to DI $(n=4)$ or salbutamol $(n=2)$.

Figure 2 shows ${ }^{3} \mathrm{He}$ MRI coronal slices at baseline, post-DI, and post-salbutamol for four representative subjects. For the subject shown without ventilation defects, there was homogeneous signal intensity over the entire lung with no obvious ventilation defects in the center MR slice or any of the anterior-to-posterior slices. For two representative subjects that showed an imaging response to DI or salbutamol, there were ventilation defects peripherally located in the central and posterior slices that resolved in response to DI or bronchodilation. For the representative subject with ventilation defects that did not appear to respond to DI or salbutamol, a number of small peripheral ventilation defects remained spatially persistent post-DI and $25 \mathrm{~min}$ after salbutamol inhalation.

For the three comparator groups (Table 1), there was no significant difference for age, sex, or body mass index. However, there was a significant difference for $\mathrm{FEV}_{1} / \mathrm{FVC}(P=$ $0.004), \mathrm{VDP},{ }^{3} \mathrm{He} \mathrm{COV}, \mathrm{VDP} \triangle \mathrm{PA}$, and PA gradient $(P<$ $0.001)$, as well as relative peripheral VDP $(P=0.001)$. There was no significant difference for any CPET or other pulmonary function measurements for the three subgroups. Post hoc analysis showed that the imaging responder group had significantly lower $\mathrm{FEV}_{1} / \mathrm{FVC}$ and significantly higher VDP, ${ }^{3} \mathrm{He} \mathrm{COV}, \mathrm{PA}$ $\triangle \mathrm{VDP}, \mathrm{PA}$ VDP gradient, and relative peripheral VDP than the no-defect and no-imaging-response groups. Figure 3 shows scatter plots for VDP, relative peripheral VDP, VDP $\triangle \mathrm{PA}$, VDP $\Delta$ SI, PA VDP gradient, SI VDP gradient, and ${ }^{3} \mathrm{He} C O V$.

Table 2 shows that 13 subjects reported significant exposure, 10 of whom $(77 \%)$ had ventilation defects. Of those 10 subjects, three showed an imaging response to DI or salbutamol. Table 2 also shows that eight never-smokers had spirometry evidence of airway obstruction (47) [Global Initiative for Chronic Obstructive Lung Disease (GOLD)-Unclassified ( $n=$ $2)$, GOLD I $(n=4)$, GOLD II $(n=2)$ ]. Five of these eight subjects reported second-hand smoke or occupational exposures, and two subjects responded to salbutamol. In addition, 10 never-smokers had $0.70 \leq \mathrm{FEV}_{1} / \mathrm{FVC} \leq 0.73$, where the 0.73 threshold was used to compensate for the variability in $\mathrm{FEV}_{1}$ and FVC $(20,29)$. The eight never-smokers with spirometry evidence of COPD had significantly greater VDP $(5.5 \pm 3.1 \%, P<0.001)$ than the never-smokers with $(\mathrm{VDP}=$ $2.5 \pm 1.2 \%)$ or without $(\mathrm{VDP}=1.6 \pm 0.7 \%)$ ventilation defects. When the subjects with spirometry evidence of COPD $(n=8)$ were removed in a sub-analysis, only VDP remained significantly different across all three subgroups $(P=0.03)$. Post hoc analysis showed that the no-imaging-response group had greater baseline VDP than the no-defect group but was not significantly different from the imaging-response group.

Pre- and post-DI/salbutamol analysis. Table 3 shows a subject listing for pre- and post-salbutamol $\mathrm{FEV}_{1}, \mathrm{VDP}$, and ${ }^{3} \mathrm{He} \mathrm{COV}$ for all subjects administered salbutamol $(n=35)$. Three subgroups were identified for those subjects adminis- 
Table 1. Baseline subject demographic and other measurements

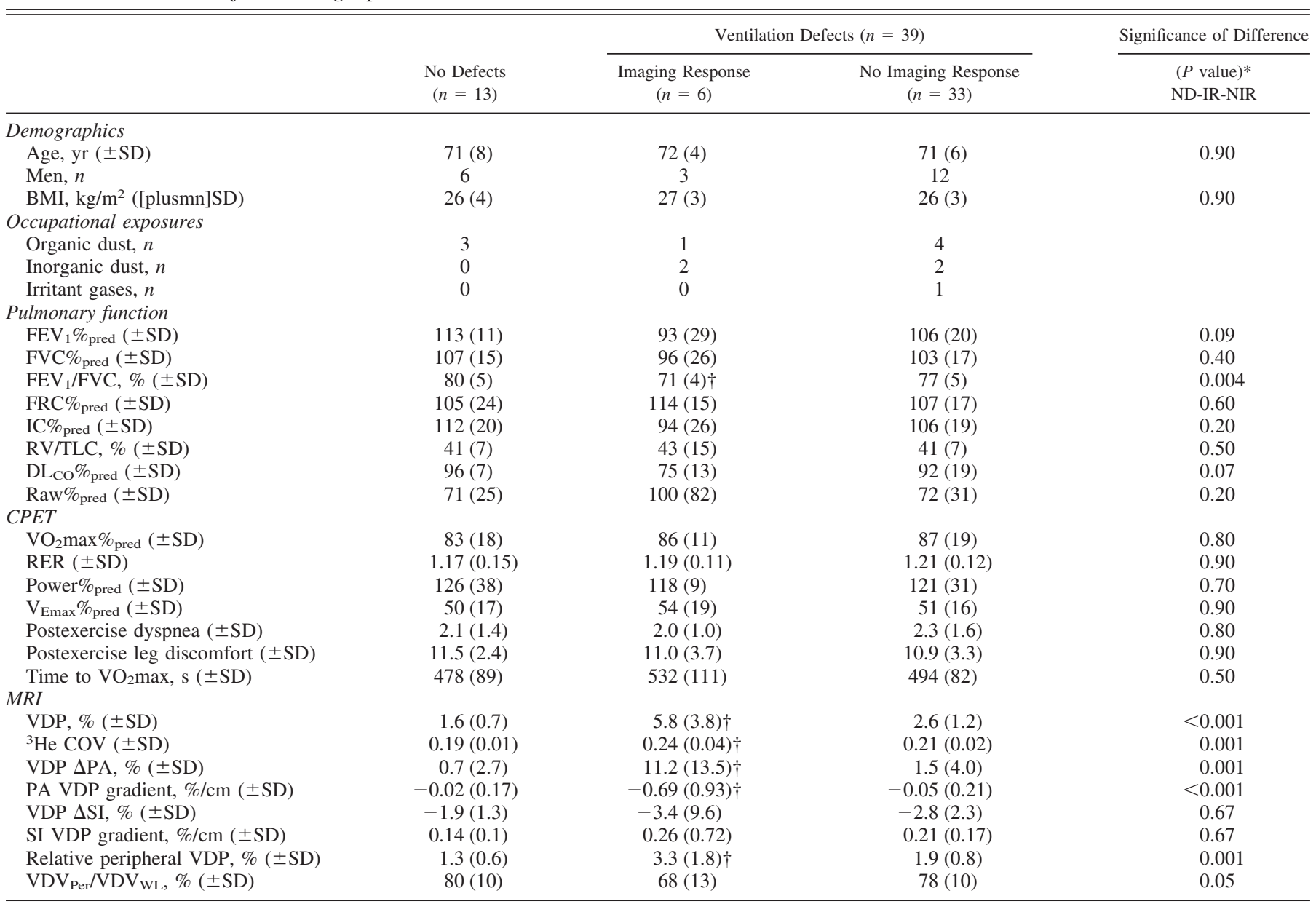

Imaging Response refers to subjects with change in ventilation-defect percent (VDP) after deep inspiration (DI) or salbutamol. No Imaging Response refers to subjects with no VDP change after salbutamol. ND, nonresponders; IR, imaging response; NIR, imaging nonresponders; BMI, body mass index; $\mathrm{FEV}_{1}$, forced expiratory in $1 \mathrm{~s}$; \% pred, percent predicted; FVC, forced vital capacity; FRC, functional residual capacity; IC, inspiratory capacity; RV, residual volume; TLC, total lung capacity; $\mathrm{DL}_{\mathrm{CO}}$, diffusing capacity of carbon monoxide; Raw, airways resistance; CPET, cardiopulmonary exercise test; $\mathrm{VO}_{2} \max$, maximal oxygen capacity; RER, respiratory exchange ratio at $\mathrm{VO}_{2} \mathrm{max}$; Power, work rate; $\mathrm{V}_{\mathrm{Emax}}$, minute ventilation at $\mathrm{VO}_{2}$ max; Time to $\mathrm{VO}_{2} \max$, time taken to reach $\mathrm{VO}_{2} \max$ during CPET; ${ }^{3} \mathrm{He} \mathrm{COV}$, ventilation coefficient of variation; VDP $\triangle \mathrm{PA}$, change in posterior and anterior VDP; VDP $\Delta$ SI, change in superior and inferior VDP; VDV Per, ventilation defect volume in the periphery of the lung; VDV $V_{\mathrm{WL}}$, VDV in the whole lung. *Significance of difference $(P<0.05)$ determined using multivariate ANOVA; †post hoc analysis conducted using Holm-Bonferroni, demonstrating significant difference between groups.

tered salbutamol: imaging responders, $\mathrm{FEV}_{1}$ responders, and nonresponders. Twenty-eight of 35 subjects did not show an imaging response or a $\mathrm{FEV}_{1}$ response to salbutamol. There were five subjects who responded to salbutamol $\left(\Delta \mathrm{FEV}_{1}>\right.$ $200 \mathrm{ml}$ ) but did not have an imaging (VDP or C1) response to salbutamol. In addition, for these five subjects, there was no significant change in any of ventilation $\mathrm{C} 2-\mathrm{C} 5$ or any combination of ventilation clusters (i.e., $\mathrm{C} 1+\mathrm{C} 2$ ) post-salbutamol. It is worth noting that one of the five $\mathrm{FEV}_{1}$ responders reported $30 \mathrm{yr}$ of occupational exposure working in the steel mill industry (S63), whereas two were lifelong farmers (S25 and S59). Finally, for those subjects administered salbutamol, there were no relationships for the change in $\mathrm{FEV}_{1}$ post-salbutamol with change in VDP $\left(r^{2}=0.04, P=0.50\right)$ or change in ${ }^{3} \mathrm{He}$ $\operatorname{COV}\left(r^{2}=0.08, P=0.10\right)$.

Table 4 shows VDP and ${ }^{3} \mathrm{He} \mathrm{COV}$ measurements for all three time points for imaging responders (DI or salbutamol responders). There were no statistically significant differences in ${ }^{3} \mathrm{He} \mathrm{COV}$ or VDP across time points for the imaging responders.

Relationships between imaging and other measurements. Table 5 shows the results of a forward, step-wise multivariate regression model using ${ }^{3} \mathrm{He}$ VDP as the dependent variable and all significant pulmonary function test measurements (obtained from the univariate analysis) as the independent variables. $\mathrm{FEV}_{1} \%_{\text {pred }}, \mathrm{IC} \%_{\text {pred }}$, and Raw\% $\%_{\text {pred }}$ were shown to predict $45 \%$ of the variability in VDP $(P=0.001)$, with $\mathrm{FEV}_{1} \%_{\text {pred }}$ making the greatest contribution. The univariate relationships are shown in Fig. 4, including $\mathrm{FEV}_{1} \%_{\text {pred }}\left(r^{2}=0.29, P<\right.$ $0.0001)$, Raw $\%_{\text {pred }}\left(r^{2}=0.29, P<0.0001\right)$, and IC\% $\%_{\text {pred }}\left(r^{2}=\right.$ $0.17, P=0.003)$. There were no statistically significant relationships for VDP with CPET, dyspnea, or occupationalexposure measurements. It is important to note that three subjects had VDP $\geq 3 \mathrm{SD}$ of the mean, and when these data were removed from the regression analysis, $\mathrm{FEV}_{1} \%_{\text {pred }}$ $\left(r^{2}=0.13, P=0.009\right)$ and IC $\%$ pred $\left(r^{2}=0.17, P=0.003\right)$ 


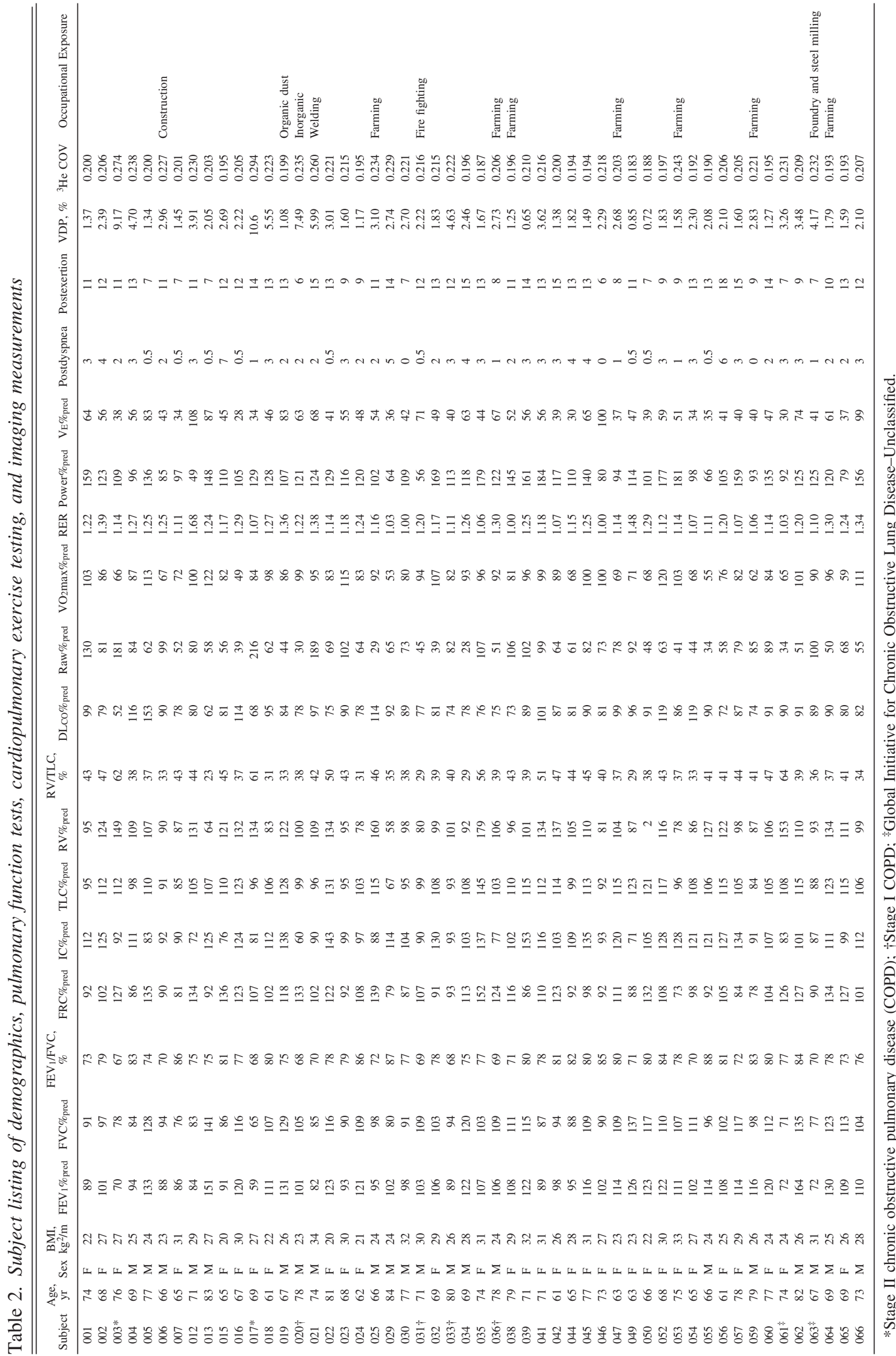


Fig. 2. ${ }^{3} \mathrm{He}$ MRI for 4 representative subjects. ${ }^{3} \mathrm{He}$ MRI ventilation (in blue) coregistered with anatomical ${ }^{1} \mathrm{H}$ MRI (gray-scale) of the center coronal slice. Subject 64 (S64) is a 69-yr-old man [forced expiratory volume in $1 \mathrm{~s}\left(\mathrm{FEV}_{1}\right)=130 \%, \mathrm{FEV}_{1} /$ forced vital capacity $(\mathrm{FVC})=78 \%$, slice number shown: 7]. S19 is a $67-y r-o l d$ man $\left(\mathrm{FEV}_{1}=\right.$ $131 \%, \mathrm{FEV}_{1} / \mathrm{FVC}=75 \%$, slice number shown: 8). S20 is a 78-yr-old man $\left(\mathrm{FEV}_{1}=\right.$ $101 \%, \mathrm{FEV}_{1} / \mathrm{FVC}=68 \%$, slice number shown: 9). S15 is a 65 -yr-old woman $\left(\mathrm{FEV}_{1}=\right.$ $91 \%, \mathrm{FEV}_{1} / \mathrm{FVC}=81 \%$, slice number shown: 8). Yellow arrows identify the position of ventilation defects. DI, deep inspiration.

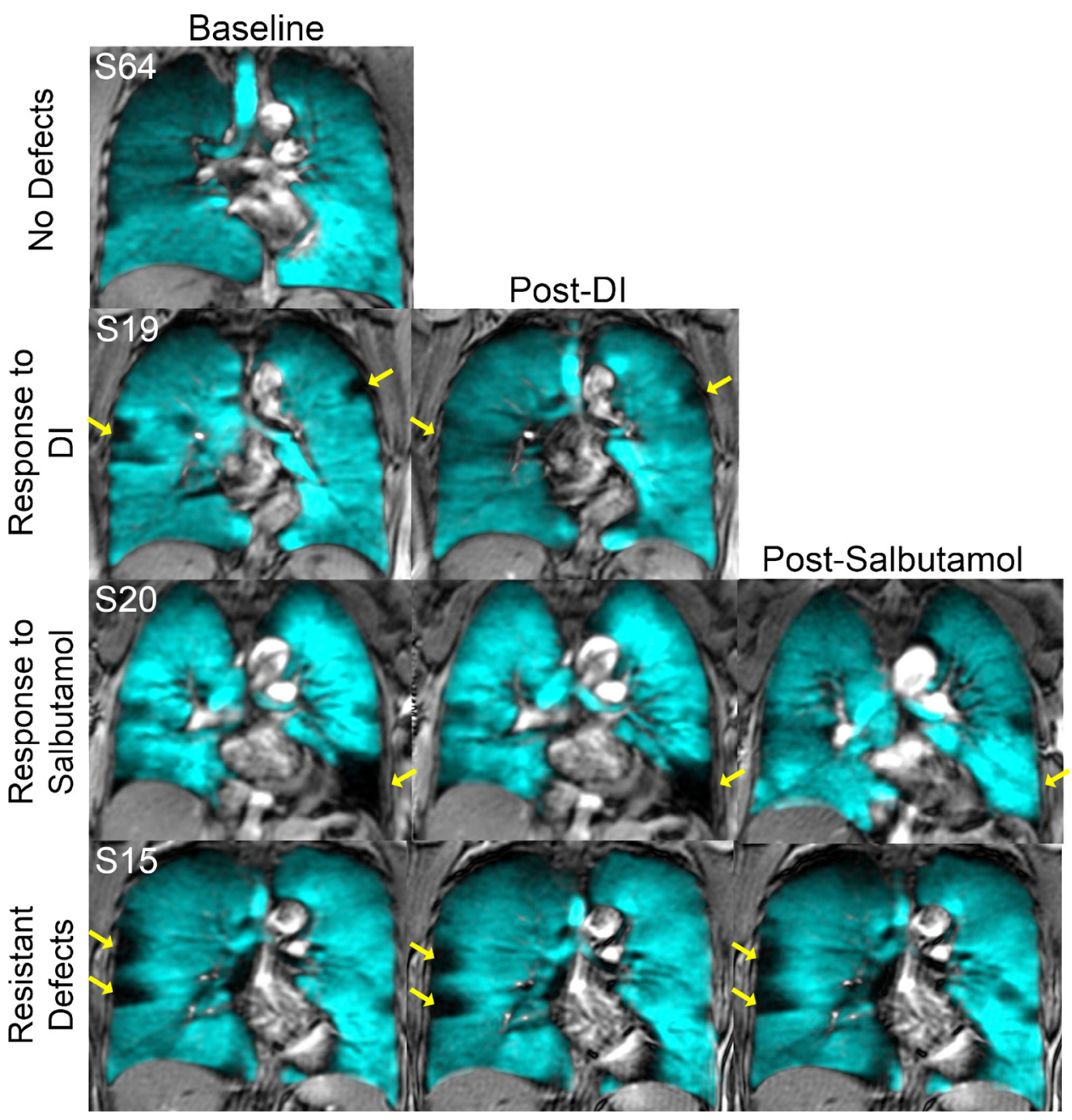

were significantly related to VDP, and Raw\% pred was not.

\section{DISCUSSION}

To understand better the determinants and physiological consequences of ventilation defects in older never-smokers, we evaluated pulmonary function and CPET measurements, as well as occupational/second-hand smoke exposure in 52 older adults. We made a number of key observations, including: 1) three-quarters of older never-smokers had ventilation defects, the majority of whom showed no VDP response to either DI or salbutamol; 2) ventilation heterogeneity and VDP were significantly greater, and $\mathrm{FEV}_{1} / \mathrm{FVC}$ was significantly lower $(P<$ 0.05 ) for subjects with ventilation defects responsive to DI/ salbutamol compared with subjects without ventilation defects and subjects with ventilation defects with no response to $\mathrm{DI} / \mathrm{salbutamol}$; and 3) in a multivariate model, $\mathrm{FEV}_{1}$, IC, and Raw explained nearly $50 \%$ of the variability in ${ }^{3} \mathrm{He}$ VDP in these older never-smokers.

Ventilation abnormalities in older never-smokers. In the 39 subjects with visually obvious ventilation defects, VDP was modest and lower than previously reported in COPD and asthma subjects; furthermore, only four subjects showed a change in VDP in response to DI. This is consistent with previous findings that showed that the bronchodilatory effects of DI decrease with age (39), which may explain the low number of DI responders in this study. Similar to previous observations in COPD (26) and asthma $(6,40)$, two subjects showed an imaging response to salbutamol, and this supports previous findings that reversible airflow limitation may be underappreciated in the elderly. Unexpectedly, the majority of older never-smokers with visually obvious ventilation defects ( $n=33$ of $39,85 \%)$ did not respond to DI or salbutamol. This is consistent with the notion that in older never-smokers, small ventilation defects are related to irreversible airway narrowing or collapse, loss of elastic recoil, and/or small peripheral regions that are slow filling.

The majority of defects was observed along the periphery of the lung, suggesting that terminal airway closure or narrowing may be a normal, age-related pulmonary finding. Relative peripheral VDP, ${ }^{3} \mathrm{He}$ COV, VDP $\triangle \mathrm{PA}$, and VDP PA gradient were significantly greater in the imaging responders compared with the nonresponder and no-defect groups. Together, these findings suggest that subjects who responded to DI or salbutamol also had greater ventilation heterogeneity (or patchiness) and greater posterior/peripheral ventilation defects. The difference in ventilation heterogeneity among groups may reflect differences in lung-filling related to airway lumen morphology, but this is yet to be determined. Other potential mechanisms for ventilation heterogeneity have been suggested, including the 

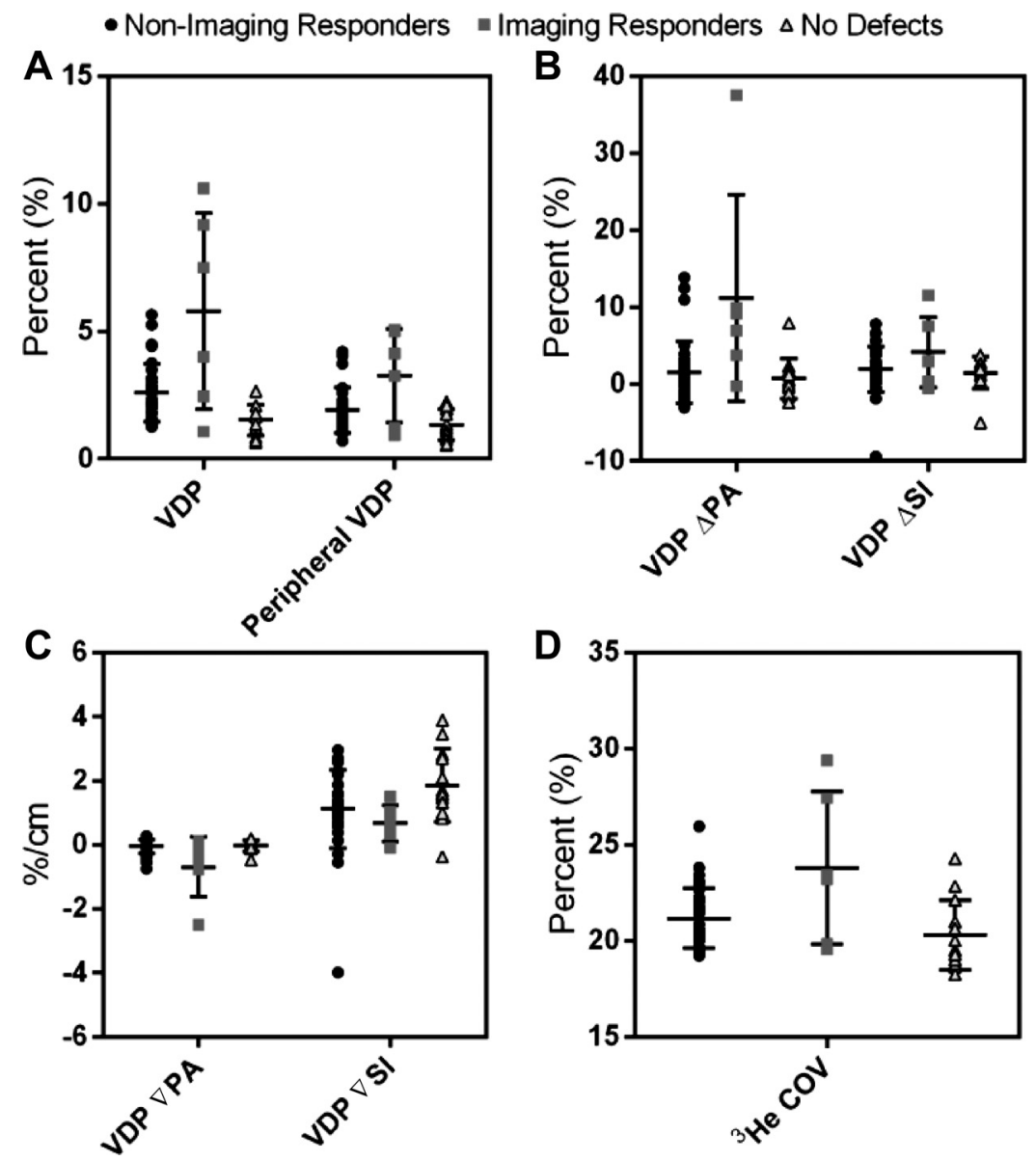

Fig. 3. Scatter plots of MRI metrics. Plots showing all MRI metrics for 3 subgroups (nonimaging responders, imaging responders, and no defects). $A$ : VDP and relative peripheral VDP, $(B)$ VDP $\triangle \mathrm{PA}$ and VDP $\Delta \mathrm{SI},(C) \mathrm{PA}$ and SI gradients, and $(D)$ ${ }^{3} \mathrm{He}$ coefficient of variation (COV). Error bars are the SD of the mean.

loss of parenchymal tethering forces due to alveolar collapse that alters airway diameters, differences in regional lung expansion due to diaphragm and ribcage motions, or gravitydependent differences in lung expansion contributing to airway constriction in the gravity-dependent regions (46). Nevertheless, in these older never-smokers, there appears to be a small, yet irreversible, VDP component. Finally, as might be expected based on the BOLD study (28), eight subjects showed spirometry evidence of COPD, and another 10 subjects exhibited $0.70 \leq \mathrm{FEV}_{1} / \mathrm{FVC} \leq 0.73\left[0.73\right.$ accounts for $\mathrm{FEV}_{1}$ and FVC variability of $2-3 \%(20,29)]$. Therefore, here, the proportion of subjects with undiagnosed airflow limitation was $35 \%$, which is in agreement with the results of the BOLD study (28). It is interesting to note that when the eight subjects with spirometry evidence of COPD were removed from the analysis, $\mathrm{FEV}_{1} / \mathrm{FVC}$ was no longer different across the three subgroups; however, VDP remained different. For five subjects

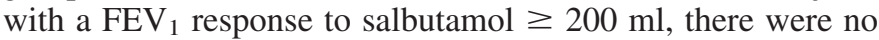
significant changes in VDP, ${ }^{3} \mathrm{He} \mathrm{COV}$, or any of the ventilation clusters (C2-C5) post-salbutamol. The discrepancy between the $\mathrm{FEV}_{1}$ response and ${ }^{3} \mathrm{He}$ MRI response may have been due to the effort-dependence of spirometry. It is also important to note that all ventilation defects were peripherally located near the distal airways, and this may also explain why salbutamol did not influence the size or magnitude of these ventilation defects.

Relationships: ventilation defects with exercise capacity and dyspnea. In this study, the range of dyspnea scores and magnitude of ventilation defects observed were small compared with recent findings in COPD and asthmatic subjects $(6,26,27$, 40). For these reasons, we were not surprised that there were no differences in CPET or dyspnea measurements between subjects with and without ventilation defects. Further supporting this finding, O'Donnell and colleagues (13) have shown that it is possible to have substantial ventilatory impairment during exercise without a corresponding effect on dyspnea. This is consistent with the notion that in healthy subjects, cardiovascular, and not respiratory factors provide the dominant contributions to exercise limitation $(7,15)$. Furthermore, unlike previous work (35), there were no relationships between dyspnea and other pulmonary function or CPET measurements that could be due to the limited range of dyspnea scores reported. Subjects with ventilation defects had normal lung function and exercise-capacity measurements for their age $(4$, $9,35)$.

Relationships: ventilation defects with pulmonary function and volumes. There were significant but weak univariate relationships for VDP with $\mathrm{FEV}_{1} \%_{\text {pred }}$, IC\% $\%_{\text {pred }}$, and Raw\% $\%_{\text {pred }}$, although the relationship between VDP and Raw\% pred was dominated by three subjects with relatively large VDP values (S3, S17, and S21). S21 had occupational and environmental exposures, and both S3 and S17 had spirometry evidence of GOLD II COPD. In a multivariate regression model, IC\% $\%_{\text {pred, }}$ Raw\% $\%_{\text {pred }}$, and $\mathrm{FEV}_{1} \%_{\text {pred }}$ all provided significant contributions to VDP, with $\mathrm{FEV}_{1} \%_{\text {pred }}$ as the strongest predictor. The negative correlation of IC\% $\%_{\text {pred }}$ with VDP is concordant with previous results in COPD ex-smokers, who showed that ab- 
Table 3. Subject listing for $F E V_{l}, V D P$, and ${ }^{3} \mathrm{He} C O V$ for all subjects administered salbutamol, $n=35$

\begin{tabular}{|c|c|c|c|c|c|c|c|c|c|c|c|c|}
\hline \multirow[b]{2}{*}{ Subject } & \multicolumn{6}{|c|}{ Pre-Salbutamol } & \multicolumn{6}{|c|}{ Post-Salbutamol } \\
\hline & Age, yr & $\mathrm{FEV}_{1}$, liter & $\mathrm{FEV}_{1} \%_{\text {pred }}$ & VDP, \% & ${ }^{3} \mathrm{He} \mathrm{COV}$ & $\mathrm{FEV}_{1}$, liter & $\mathrm{FEV}_{1} \%_{\text {pred }}$ & VDP, \% & ${ }^{3} \mathrm{He} \mathrm{COV}$ & $\Delta \mathrm{FEV}_{1}$, liter & $\Delta \mathrm{FEV}_{1} \%_{\text {pred }}$ & $\Delta \mathrm{VDP}, \%$ \\
\hline 001 & 74 & 1.68 & 89 & 1.35 & 0.20 & 1.70 & 91 & 0.84 & 0.20 & 0.02 & 2 & -0.51 \\
\hline $002 *$ & 68 & 2.52 & 101 & 2.34 & 0.21 & 2.72 & 109 & 1.65 & 0.20 & 0.20 & 8 & -0.69 \\
\hline 003 & 76 & 1.30 & 70 & 9.17 & 0.27 & 1.34 & 72 & 8.15 & 0.28 & 0.04 & 2 & -1.02 \\
\hline 004 & 69 & 3.33 & 94 & 4.49 & 0.24 & 3.31 & 94 & 4.02 & 0.24 & -0.02 & 0 & -0.47 \\
\hline 005 & 77 & 3.36 & 133 & 1.32 & 0.20 & 3.06 & 122 & 1.55 & 0.21 & -0.30 & -11 & 0.23 \\
\hline 006 & 66 & 3.30 & 88 & 2.87 & 0.23 & 3.29 & 88 & 2.73 & 0.22 & -0.01 & 0 & -0.14 \\
\hline 007 & 65 & 2.01 & 86 & 1.43 & 0.20 & 2.08 & 89 & 2.11 & 0.22 & 0.07 & 3 & 0.68 \\
\hline 012 & 71 & 2.78 & 84 & 3.76 & 0.23 & 2.66 & 81 & 2.87 & 0.23 & -0.12 & -3 & -0.90 \\
\hline 015 & 65 & 2.38 & 91 & 2.61 & 0.20 & 2.52 & 96 & 2.29 & 0.21 & 0.14 & 5 & -0.33 \\
\hline 016 & 67 & 3.80 & 120 & 2.22 & 0.21 & 3.88 & 123 & 1.65 & 0.22 & 0.08 & 3 & -0.57 \\
\hline $017^{+}$ & 69 & 1.24 & 59 & 10.6 & 0.29 & 1.35 & 64 & 7.91 & 0.27 & 0.11 & 5 & -2.70 \\
\hline 018 & 61 & 3.06 & 111 & 5.26 & 0.22 & 3.14 & 114 & 5.62 & 0.24 & 0.08 & 3 & 0.36 \\
\hline $020^{+}$ & 78 & 2.76 & 101 & 7.49 & 0.24 & 3.02 & 110 & 3.47 & 0.24 & 0.26 & 9 & -4.02 \\
\hline 021 & 74 & 2.32 & 82 & 5.65 & 0.26 & 2.41 & 85 & 3.25 & 0.25 & 0.09 & 3 & -2.40 \\
\hline $022 *$ & 81 & 2.18 & 123 & 2.92 & 0.22 & 2.43 & 137 & 5.37 & 0.23 & 0.25 & 14 & 2.45 \\
\hline 023 & 68 & 1.96 & 93 & 1.57 & 0.22 & 2.09 & 99 & 1.25 & 0.21 & 0.13 & 6 & -0.32 \\
\hline $025^{*}$ & 66 & 3.54 & 95 & 3.01 & 0.23 & 3.78 & 102 & 2.33 & 0.22 & 0.24 & 7 & -0.68 \\
\hline 031 & 71 & 3.14 & 103 & 2.17 & 0.22 & 3.15 & 103 & 1.93 & 0.22 & 0.01 & 0 & -0.24 \\
\hline 032 & 69 & 2.75 & 106 & 1.79 & 0.22 & 2.82 & 109 & 1.56 & 0.21 & 0.07 & 3 & -0.24 \\
\hline 033 & 80 & 2.86 & 89 & 4.42 & 0.22 & 2.76 & 86 & 6.13 & 0.23 & -0.10 & -3 & 1.71 \\
\hline 036 & 78 & 2.88 & 106 & 2.73 & 0.21 & 3.06 & 112 & 1.92 & 0.20 & 0.18 & 6 & -0.81 \\
\hline 041 & 71 & 2.19 & 89 & 3.49 & 0.22 & 2.31 & 94 & 3.38 & 0.22 & 0.12 & 5 & -0.11 \\
\hline 044 & 65 & 2.24 & 95 & 1.79 & 0.19 & 2.14 & 90 & 1.84 & 0.22 & -0.10 & -5 & 0.05 \\
\hline 045 & 77 & 2.44 & 116 & 1.46 & 0.19 & 2.31 & 109 & 2.02 & 0.21 & -0.13 & -7 & 0.55 \\
\hline 046 & 73 & 2.06 & 102 & 2.35 & 0.22 & 1.90 & 94 & 2.14 & 0.22 & -0.16 & -8 & -0.21 \\
\hline 047 & 63 & 2.52 & 114 & 2.61 & 0.20 & 2.53 & 116 & 3.09 & 0.20 & 0.01 & 2 & 0.48 \\
\hline 052 & 68 & 2.55 & 122 & 1.83 & 0.20 & 2.63 & 125 & 1.58 & 0.19 & 0.08 & 3 & -0.25 \\
\hline 054 & 65 & 2.42 & 102 & 2.24 & 0.19 & 2.49 & 105 & 3.33 & 0.20 & 0.07 & 3 & 1.08 \\
\hline 056 & 61 & 3.12 & 108 & 2.10 & 0.21 & 3.19 & 110 & 1.90 & 0.21 & 0.07 & 2 & -0.20 \\
\hline 057 & 78 & 2.23 & 114 & 1.58 & 0.21 & 2.27 & 116 & 1.29 & 0.21 & 0.04 & 2 & -0.28 \\
\hline $059 *$ & 79 & 2.53 & 116 & 2.83 & 0.22 & 2.73 & 125 & 2.90 & 0.22 & 0.20 & 9 & 0.07 \\
\hline 060 & 77 & 2.36 & 120 & 1.26 & 0.20 & 2.37 & 121 & 1.55 & 0.20 & 0.01 & 1 & 0.29 \\
\hline 061 & 74 & 1.53 & 72 & 3.15 & 0.23 & 1.59 & 75 & 5.21 & 0.24 & 0.06 & 3 & 2.03 \\
\hline $063 *$ & 67 & 2.46 & 72 & 4.00 & 0.23 & 2.94 & 86 & 3.72 & 0.22 & 0.48 & 14 & -0.28 \\
\hline 065 & 69 & 2.57 & 109 & 1.59 & 0.19 & 2.70 & 114 & 1.79 & 0.20 & 0.13 & 5 & 0.20 \\
\hline Imaging responders ${ }^{\dagger}$ & 74 & 2.0 & 80 & 9.0 & 0.27 & 2.2 & 87 & 5.7 & 0.26 & 0.2 & 7.0 & -3.4 \\
\hline Mean (SD), $n=2$ & (6) & (1.1) & (30) & $(2.2)$ & $(0.04)$ & $(1.2)$ & (33) & $(3.0)$ & $(0.02)$ & $(0.1)$ & $(2.8)$ & $(0.9)$ \\
\hline$F E V_{1}$ responders $*$ & 74 & 2.7 & 102 & 3.1 & 0.22 & 3.0 & 112 & 3.3 & 0.22 & 0.3 & 10.0 & 0.2 \\
\hline Mean (SD), $n=5$ & (7) & $(0.5)$ & (20) & $(0.5)$ & $(0.01)$ & $(0.5)$ & (20) & (1.3) & $(0.01)$ & $(0.1)$ & $(3.8)$ & $(1.3)$ \\
\hline Nonresponders & 71 & 2.5 & 100 & 2.8 & 0.21 & 2.5 & 101 & 2.7 & 0.22 & 0.00 & 1.0 & -0.04 \\
\hline Mean (SD) $n=28$ & (5) & $(0.6)$ & (16) & $(1.7)$ & $(0.02)$ & $(0.6)$ & (15) & (1.7) & $(0.02)$ & $(0.1)$ & $(4.4)$ & $(0.8)$ \\
\hline
\end{tabular}

normal IC is a marker of expiratory flow limitation and a predictor of dynamic hyperinflation during exercise (31). An increase in dynamic hyperinflation results in an increased elastic load on the inspiratory muscles, thus increasing the work and cost of breathing. This mechanical constraint can predispose individuals to fatigue, and it has been shown that dynamic hyperinflation contributes to perceived exertional dyspnea in subjects with $\operatorname{COPD}(31,32,34)$. It is also interesting to note that resting IC can predict the peak, symptom-limited $\mathrm{VO}_{2}$ in patients with expiratory flow limitation at rest (34).

Table 4. VDP and ${ }^{3} \mathrm{He} \mathrm{COV}$ measurements for imaging responders

\begin{tabular}{lccc}
\hline \hline & Baseline & Post-DI & Post-Salbutamol \\
\hline Imaging responders, $\mathrm{n}=6$ & $5.8(3.8)$ & $4.7(2.6)$ & \\
VDP, \% $( \pm \mathrm{SD})$ & $0.24(0.04)$ & $0.24(0.04)$ & $0.25(3.1)$ \\
${ }^{3} \mathrm{He}$ COV $( \pm \mathrm{SD})$ & & & \\
DI responders, $\mathrm{n}=4$ & & $3.5(2.3)$ & \\
$\mathrm{VDP}, \%( \pm \mathrm{SD})$ & $4.2(3.5)$ & $0.23(0.04)$ & \\
${ }^{3} \mathrm{He}$ COV $( \pm \mathrm{SD})$ & $0.23(0.04)$ & & \\
Salbutamol responders, $\mathrm{n}=2.0(1.0)$ & $5.7(3.1)$ \\
VDP, \% $( \pm \mathrm{SD})$ & $9.0(2.2)$ & $0.25(0.03)$ & $0.25(0.02)$ \\
${ }^{3} \mathrm{He} \mathrm{COV}( \pm \mathrm{SD})$ & $0.26(0.04)$ & & \\
\hline
\end{tabular}

Limitations. We recognize a number of limitations that restrict the general applicability of our results. First, subjects were classified by viewing the gray-scale images, while the patients were still in the scanner. Offline, once the ventilation images were coregistered to the anatomical ${ }^{1} \mathrm{H}$ images, in two cases, previously classified ventilation defects could be directly related to anatomical bony structures and were unlikely to be ventilation abnormalities. As a result, two subjects, who were classified at the scanner as having ventilation defects, did not appear to have these once a full analysis was completed, although both completed DI and salbutamol inhalation. One

Table 5. Univariate and multivariate relationships for ${ }^{3} \mathrm{He}$ MRI VDP with pulmonary function measurements

\begin{tabular}{lcc}
\hline \hline \multirow{2}{*}{ Parameters } & Univariate Relationship & \\
& VDP & Multivariate Model VDP \\
\hline FEV $_{1} \%_{\text {pred }}$ & $r^{2}(P$ value $)$ & $\beta, r^{2}, \Delta r^{2}(P$ value $)$ \\
Raw $\%_{\text {pred }}$ & $0.29(<0.001)$ & $-0.541,0.292,0.292(<0.001)$ \\
IC\% $\%_{\text {pred }}$ & $0.29(<0.001)$ & $0.359,0.391,0.099(<0.001)$ \\
FEV $/$ FVC, $\%$ & $0.17(0.003)$ & $-0.265,0.449,0.058(<0.001)$ \\
FVC\% $\%$ pred & $0.17(0.002)$ & $-0.147,0.449,0(0.23)$ \\
RV/TLC, $\%$ & $0.24(<0.002)$ & $0.114,0.449,0(0.68)$ \\
& $0.15(0.005)$ & $0.105,0.449,0(0.44)$ \\
\hline
\end{tabular}



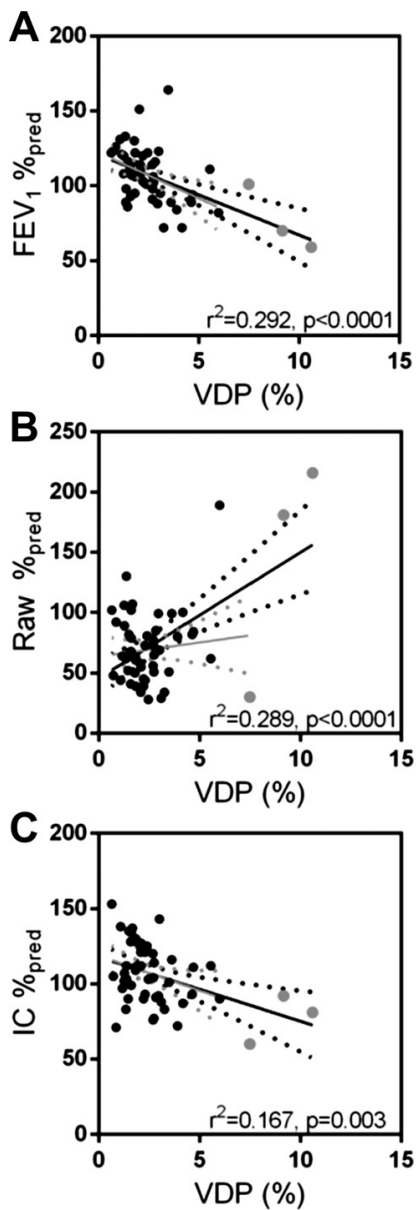

Fig. 4. Univariate correlations for VDP with: $(A)$ predicted $\mathrm{FEV}_{1}$ percent $\left(\mathrm{FEV}_{1} \%\right.$ pred $)$ for all subjects $\left(r^{2}=0.29, r=-0.54, P<0.0001\right)$; $(B)$ airway resistance (Raw) $\%_{\text {pred }}$ for all subjects $\left(r^{2}=0.29, \mathrm{r}=0.54, P<0.0001\right)$; and (C) inspiratory capacity (IC) $\%_{\text {pred }}$ for all subjects $\left(r^{2}=0.17, \mathrm{r}=-0.41, P=\right.$ $0.003)$. The black regression lines are the result of when all subjects were included in the analysis. Gray circles show the subjects with VDP $>3$ SD of the mean. The gray regression lines show the alternate regression, resulting when these subjects were excluded.

subject had ventilation defects that responded to DI (but not salbutamol), whereas the other subject had no ventilation defects and did not respond to DI or salbutamol. We did not remove these subjects from the analysis, and their inclusion did not alter the final overall results. It should also be noted that since all subjects were imaged $\sim 30$ min after completion of CPET, ventilation defects and ventilation heterogeneity may have been influenced by exercise. Previous studies have shown that during exercise, athletes experience ventilation-perfusion mismatch and diffusion limitation (18). Other studies have evaluated the progression of ventilation-perfusion mismatch after exercise and showed that some subjects do not recover fully from ventilation-perfusion mismatch until 20 min postexercise (38). Because of the time delay between imaging and CPET and the fact that in this study, VDP did not correlate with any CPET measurements, it is unlikely that prior exercise influenced the presence or absence of ${ }^{3} \mathrm{He}$ MRI ventilation defects.

Conclusions. In summary, we evaluated hyperpolarized ${ }^{3} \mathrm{He}$ MRI ventilation defects - a surrogate measurement of airway function-in the first large imaging study of healthy, older never-smokers with no history of chronic heart or lung disease. Whereas a minority of subjects reported occupational exposures, most subjects had visually obvious ventilation defects that did not change after DI or salbutamol administration, suggesting that terminal airway closure or narrowing may be a normal, age-related lung finding. Whereas there were no differences in CPET or conventional pulmonary function measurements between subjects with and without ventilation defects, $\mathrm{FEV}_{1} \%_{\text {pred }}$, in combination with IC\% $\%_{\text {pred }}$ and Raw\% $\%_{\text {pred, }}$ predicted VDP in a multivariate regression model. Taken together, these findings provide a better understanding of the nature of ventilation defects in healthy, older never-smokers.

\section{ACKNOWLEDGMENTS}

We thank S. Blamires and D. Buchanan for clinical coordination and clinical database management, A. Wheatley for gas-contrast dispensing and administration, and T. Szekeres for MRI of research volunteers.

\section{GRANTS}

Support is gratefully acknowledged from G. Parraga for a Canadian Institutes of Health Research (CIHR) New Investigator Award and ongoing research funding from CIHR Operating Grant MOP 106437.

\section{DISCLOSURES}

The authors have no conflicts of interest.

\section{AUTHOR CONTRIBUTIONS}

Author contributions: G.P. conception and design of research; K.S. and S.S. performed experiments; K.S., G.A.P., and G.P. analyzed data; K.S., G.A.P., S.S., M.K., and G.P. interpreted results of experiments; K.S. prepared figures; K.S., G.A.P., and G.P. drafted manuscript; K.S., G.A.P., S.S., M.K., N.A.M.P., D.G.M., and G.P. edited and revised manuscript; K.S., G.A.P., S.S., M.K., N.A.M.P., D.G.M., and G.P. approved final version of manuscript.

\section{REFERENCES}

1. Ahmed T, Steward JA, O'Mahony MS. Dyspnoea and mortality in older people in the community: a 10-year follow-up. Age Ageing 41: 545-549, 2012.

3. Albouaini K, Egred M, Alahmar A, Wright DJ. Cardiopulmonary exercise testing and its application. Postgrad Med J 83: 675-682, 2007.

3a.American Thoracic Society; American College of Chest Physicians. Statement on cardiopulmonary exercise testing. Am J Respir Crit Care Med 167: 211-277, 2003.

4. Astrand I, Astrand PO, Hallback I, Kilbom A. Reduction in maximal oxygen uptake with age. J Appl Physiol 35: 649-654, 1973.

5. Buist AS, Vollmer WM, Sullivan SD, Weiss KB, Lee TA, Menezes AM, Crapo RO, Jensen RL, Burney PG. The Burden of Obstructive Lung Disease Initiative (BOLD): rationale and design. COPD 2: 277-283, 2005 .

6. Costella S, Kirby M, Maksym GN, McCormack DG, Paterson NA, Parraga G. Regional pulmonary response to a methacholine challenge using hyperpolarized (3)He magnetic resonance imaging. Respirology 17: 1237-1246, 2012.

7. Dempsey JA, Hanson PG, Henderson KS. Exercise-induced arterial hypoxaemia in healthy human subjects at sea level. $J$ Physiol 355: 161-175, 1984.

8. Enright PL, Kronmal RA, Manolio TA, Schenker MB, Hyatt RE. Respiratory muscle strength in the elderly. Correlates and reference values. Cardiovascular Health Study Research Group. Am J Respir Crit Care Med 149: 430-438, 1994.

9. Fletcher C, Peto R. The natural history of chronic airflow obstruction. $\mathrm{Br}$ Med J 1: 1645-1648, 1977.

10. Frank NR, Mead J, Ferris BG Jr. The mechanical behavior of the lungs in healthy elderly persons. J Clin Invest 36: 1680-1687, 1957.

11. Guazzi M, Adams V, Conraads V, Halle M, Mezzani A, Vanhees L, Arena R, Fletcher GF, Forman DE, Kitzman DW, Lavie CJ, Myers J. EACPR/AHA Scientific Statement. Clinical recommendations for cardiopulmonary exercise testing data assessment in specific patient populations. Circulation 126: 2261-2274, 2012. 
12. Guenette JA, Chin RC, Cory JM, Webb KA, O'Donnell DE. Inspiratory capacity during exercise: measurement, analysis, and interpretation. Pulm Med 2013: 956081, 2013.

13. Guenette JA, Diane Lougheed M, Webb KA, O'Donnell DE. Can an 86-year-old woman with advanced lung disease be a world class athlete? Respir Physiol Neurobiol 181: 162-166, 2012.

14. Hankinson JL, Odencrantz JR, Fedan KB. Spirometric reference values from a sample of the general U.S. population. Am J Respir Crit Care Med 159: 179-187, 1999.

15. Harms CA, Wetter TJ, St Croix CM, Pegelow DF, Dempsey JA. Effects of respiratory muscle work on exercise performance. J Appl Physiol (1985) 89: 131-138, 2000.

16. Heath GW, Hagberg JM, Ehsani AA, Holloszy JO. A physiological comparison of young and older endurance athletes. J Appl Physiol Respir Environ Exerc Physiol 51: 634-640, 1981.

17. Ho SF, O'Mahony MS, Steward JA, Breay P, Buchalter M, Burr ML. Dyspnoea and quality of life in older people at home. Age Ageing 30: 155-159, 2001.

18. Hopkins SR, McKenzie DC, Schoene RB, Glenny RW, Robertson HT. Pulmonary gas exchange during exercise in athletes. I. Ventilation-perfusion mismatch and diffusion limitation. J Appl Physiol (1985) 77: 912 917, 1994.

19. Huijnen B, van der Horst F, van Amelsvoort L, Wesseling G, Lansbergen M, Aarts P, Nicolson N, Knottnerus A. Dyspnea in elderly family practice patients. Occurrence, severity, quality of life and mortality over an 8-year period. Fam Pract 23: 34-39, 2006.

20. Humerfelt S, Eide GE, Kvale G, Gulsvik A. Forced expiratory volume in $1 \mathrm{~s}$ (FEV1) and forced vital capacity (FVC) variability in asymptomatic never-smoking men. Clin Physiol 18: 387-396, 1998.

21. Janssens JP, Pache JC, Nicod LP. Physiological changes in respiratory function associated with ageing. Eur Respir J 13: 197-205, 1999.

22. Jensen A, Atileh H, Suki B, Ingenito EP, Lutchen KR. Selected contribution: airway caliber in healthy and asthmatic subjects: effects of bronchial challenge and deep inspirations. J Appl Physiol (1985) 91: 506-515; discussion 504-505, 2001.

23. Jensen D, Ofir D, O'Donnell DE. Effects of pregnancy, obesity and aging on the intensity of perceived breathlessness during exercise in healthy humans. Respir Physiol Neurobiol 167: 87-100, 2009.

24. Kasch FW, Boyer JL, Van Camp S, Nettl F, Verity LS, Wallace JP. Cardiovascular changes with age and exercise. A 28-year longitudinal study. Scand J Med Sci Sports 5: 147-151, 1995.

25. Kirby M, Heydarian M, Svenningsen S, Wheatley A, McCormack DG, Etemad-Rezai R, Parraga G. Hyperpolarized 3He magnetic resonance functional imaging semiautomated segmentation. Acad Radiol 19: 141-152, 2012.

26. Kirby M, Mathew L, Heydarian M, Etemad-Rezai R, McCormack DG, Parraga G. Chronic obstructive pulmonary disease: quantification of bronchodilator effects by using hyperpolarized (3)He MR imaging. Radiology 261: 283-292, 2011.

27. Kirby M, Mathew L, Wheatley A, Santyr GE, McCormack DG, Parraga G. Chronic obstructive pulmonary disease: longitudinal hyperpolarized (3)He MR imaging. Radiology 256: 280-289, 2010.

28. Lamprecht B, McBurnie MA, Vollmer WM, Gudmundsson G, Welte T, Nizankowska-Mogilnicka E, Studnicka M, Bateman E, Anto JM, Burney P, Mannino DM, Buist SA. COPD in never smokers: results from the population-based burden of obstructive lung disease study. Chest 139: 752-763, 2011.

29. Margaret R, Becklake SP. Evaluation of Tests of Lung Function for Screening for Early Detection of Chronic Obstructive Lung Disease. New York: Marcel Dekker, 1979, p. 345-388.
30. Nejjari C, Tessier JF, Dartigues JF, Barberger-Gateau P, Letenneur L, Salamon R. The relationship between dyspnoea and main lifetime occupation in the elderly. Int J Epidemiol 22: 848-854, 1993.

31. O'Donnell DE, Bertley JC, Chau LK, Webb KA. Qualitative aspects of exertional breathlessness in chronic airflow limitation: pathophysiologic mechanisms. Am J Respir Crit Care Med 155: 109-115, 1997.

32. O'Donnell DE, Laveneziana P. Dyspnea and activity limitation in COPD: mechanical factors. COPD 4: 225-236, 2007.

33. O'Donnell DE, O'Donnell CD, Webb KA, Guenette JA. Respiratory consequences of mild-to-moderate obesity: impact on exercise performance in health and in chronic obstructive pulmonary disease. Pulm Med 2012: 818925, 2012.

34. O'Donnell DE, Revill SM, Webb KA. Dynamic hyperinflation and exercise intolerance in chronic obstructive pulmonary disease. Am J Respir Crit Care Med 164: 770-777, 2001.

35. Ofir D, Laveneziana P, Webb KA, Lam YM, O'Donnell DE. Sex differences in the perceived intensity of breathlessness during exercise with advancing age. J Appl Physiol (1985) 104: 1583-1593, 2008.

36. Parraga G, Mathew L, Etemad-Rezai R, McCormack DG, Santyr GE. Hyperpolarized $3 \mathrm{He}$ magnetic resonance imaging of ventilation defects in healthy elderly volunteers: initial findings at 3.0 Tesla. Acad Radiol 15: 776-785, 2008.

37. Parraga G, Ouriadov A, Evans A, McKay S, Lam WW, Fenster A, Etemad-Rezai R, McCormack D, Santyr G. Hyperpolarized 3He ventilation defects and apparent diffusion coefficients in chronic obstructive pulmonary disease: preliminary results at 3.0 Tesla. Invest Radiol 42: 384-391, 2007.

38. Schaffartzik W, Poole DC, Derion T, Tsukimoto K, Hogan MC, Arcos JP, Bebout DE, Wagner PD. VA/Q distribution during heavy exercise and recovery in humans: implications for pulmonary edema. $J \mathrm{Appl}$ Physiol (1985) 72: 1657-1667, 1992.

39. Scichilone N, Marchese R, Catalano F, Togias A, Vignola AM, Bellia V. The bronchodilatory effect of deep inspiration diminishes with aging. Respir Med 98: 838-843, 2004.

40. Svenningsen S, Kirby M, Starr D, Leary D, Wheatley A, Maksym GN, McCormack DG, Parraga G. Hyperpolarized He and Xe MRI: differences in asthma before bronchodilation. J Magn Reson Imaging 38: 1521-1530, 2013.

41. Tessier JF, Nejjari C, Letenneur L, Filleul L, Marty ML, Barberger Gateau P, Dartigues JF. Dyspnea and 8-year mortality among elderly men and women: the PAQUID cohort study. Eur J Epidemiol 17: $223-$ 229, 2001.

42. Thurlbeck WM. Internal surface area and other measurements in emphysema. Thorax 22: 483-496, 1967.

43. Turner JM, Mead J, Wohl ME. Elasticity of human lungs in relation to age. J Appl Physiol (1985) 25: 664-671, 1968.

44. Tzeng YS, Lutchen K, Albert M. The difference in ventilation heterogeneity between asthmatic and healthy subjects quantified using hyperpolarized 3He MRI. J Appl Physiol (1985) 106: 813-822, 2009.

45. VanBell GFL, Heagerty P, Lumley T. Multiple comparisons. In :Biostatistics: A Methodology for the Health Sciences. Seattle, WA: WileyInterscience, 2004.

46. Venegas JG, Winkler T, Musch G, Vidal Melo MF, Layfield D, Tgavalekos N, Fischman AJ, Callahan RJ, Bellani G, Harris RS. Self-organized patchiness in asthma as a prelude to catastrophic shifts. Nature 434: 777-782, 2005.

47. Wan ES, Hokanson JE, Murphy JR, Regan EA, Make BJ, Lynch DA, Crapo JD, Silverman EK. Clinical and radiographic predictors of GOLD-unclassified smokers in the COPDGene study. Am J Respir Crit Care Med 184: 57-63, 2011. 